\title{
Factors affecting the attachment of Treponema pallidum to mammalian cells in vitro
}

\author{
G H W WONG, B STEINER, S FAINE, AND S GRAVES \\ From the Department of Microbiology, Monash University Medical School, Alfred Hospital, Prahran, \\ Victoria, Australia
}

SUMMARY Attachment of Treponema pallidum (Nichols) to mammalian cells is probably the first step in the pathogenesis of syphilis. It may also be important for the multiplication of T pallidum in vitro. When factors affecting the attachment of $T$ pallidum to mammalian cells in vitro were studied significantly greater numbers of treponemes were found to attach to baby rabbit genital organ (BRGO) cells than to five other mammalian cell lines. When attached to BRGO cells $T$ pallidum survived longer in vitro than unattached treponemes. Eagle's minimal essential medium was superior to three other culture media in increasing attachment and maintaining the survival of treponemes. Dithiothreitol $(0.25-1.0 \mathrm{mmol} / \mathrm{l})$ had no effect on the attachment of $T$ pallidum to BRGO cells. Anaerobic conditions were superior to microaerophilic conditions, and the latter were superior to aerobic conditions for the attachment and survival of $T$ pallidum to BRGO cells. Within the range of concentrations tested the number of treponemes attached to the BRGO cells was directly dependent on the concentrations of viable treponemes in the inoculum. Greater numbers of treponemes attached to actively metabolising BRGO cells than to quiescent or slowly growing cells.

\section{Introduction}

$T$ pallidum attaches to a variety of mammalian cells, thereby enhancing its own survival ${ }^{12}$ and cultivation of $T$ pallidum in vitro using different tissue-culture systems has been reported. ${ }^{34} \mathrm{~A}$ relationship between attachment and the pathogenicity of $T$ pallidum has been suggested ${ }^{5}$ and the attachment process appears to require both actively metabolising host cells and viable treponemes. ${ }^{6}$ Only virulent treponemes can attach to host cells, such attachment probably being the initial step in infection. ${ }^{1}$

Fieldsteel et $a l^{7}$ observed that only treponemes attached to mammalian cells were able to multiply in vitro. Thus, studies of attachment of treponemes to host cells may extend our understanding of the pathogenesis and host-parasite interaction in syphilis and facilitate the successful subculture of $T$ pallidum in vitro. In this study different factors affecting the attachment of $T$ pallidum to tissue culture cells were investigated.

\footnotetext{
Address for reprints: Dr S Graves, Department of Microbiology, Monash University Medical School, Alfred Hospital, Prahran, Victoria 3181, Australia
}

Accepted for publication 18 August 1982

\section{Materials and methods}

MAINTENANCE OF T PALLIDUM

$T$ pallidum was maintained in adult male rabbits as described. ${ }^{8}$ Treponemes were extracted anaerobically ${ }^{9}$ and centrifuged at $1000 \times g$ for 10 minutes to remove rabbit testicular cells and erythrocytes. The concentration of $T$ pallidum was determined by enumeration in a bacterial counting chamber using dark-field microscopy.

\section{ISOLATION AND MAINTENANCE OF TISSUE-}

CULTURE CELLS

Six different cell lines were used for comparison of $T$ pallidum attachment. Primary baby rabbit genital organ (BRGO) and adult rabbit testicular (RT) cell cultures were propagated in our laboratory. The tissues were cut, minced, and stirred in phosphatebuffered saline (PBS) containing $0.025 \%$ trypsin (Sigma) and $100 \mathrm{U} / \mathrm{ml}$ of penicillin and streptomycin (Glaxo) at $37^{\circ} \mathrm{C}$ for 30 minutes. The cells were collected, centrifuged at $1000 \times g$ for 10 minutes, and resuspended in Eagle's minimal essential medium (EMEM) supplemented with $20 \%$ heat-inactivated fetal calf serum (FCS), $10 \mathrm{mmol} / 1 \mathrm{~N}$-2-hydroxyethylpiperazine-N-2-ethane-sulphonic-acid (HEPES), and antibiotics as above. The cells were then grown in $10 \%$ 
FCS without antibiotics at $34^{\circ} \mathrm{C}$ and the medium changed every three days. The confluent monolayers were subcultured using PBS containing $0.025 \%$ trypsin and $0.001 \%$ ethylenediamine tetra-acetic acid (Sigma) to remove cells from the glass.

The baby hamster kidney (BHK) cell line was a gift from Mr K Stuckly, Department of Microbiology, Monash University. Three human tumour cell lines, skin tumour (C76/203), colon tumour (HT29), and breast tumour (MCF-7), were gifts from Professor E A V Pihl, Department of Pathology and Immunology, Monash University. All cell lines were maintained in EMEM with $10 \%$ FCS and $10 \mathrm{mmol} / 1$ HEPES without antibiotics. Carbon dioxide and sodium bicarbonate were not used for maintenance of cell lines or for co-incubation of $T$ pallidum with tissue culture cells. ${ }^{10}$ EMEM with $10 \%$ FCS, $10 \mathrm{mmol} / 1$ HEPES, and $0.5 \mathrm{mmol} / 1$ dithiothreitol (DTT) was used for all experiments unless otherwise specified.

\section{CO-INCUBATION OF T PALLIDUM AND CULTURED CELLS}

Mammalian cells $\left(1-5 \times 10^{4}\right)$ were seeded into Leighton tubes containing a coverslip $(8 \times 32 \mathrm{~mm})$ one or two days before experimental use. Cells were then washed twice with medium before inoculation with $T$ pallidum. Co-incubation was carried out at $34^{\circ} \mathrm{C}$ under aerobic $\left(21 \% \mathrm{O}_{2}\right)$, microaerophilic $\left(3 \% \mathrm{O}_{2}\right)$, or anaerobic conditions, the latter two as described. ${ }^{8}$

\section{DETERMINATION OF TREPONEMAL VIABILITY AND NUMBER OF ATTACHED TREPONEMES PER MAMMALIAN CELL}

Survival of treponemes was determined by their retention of motility and virulence, the latter measured by rabbit inoculation. Approximately 100 treponemes randomly selected from duplicate or triplicate tubes were examined by dark-field microscopy to determine the percentage of motile treponemes in the sample. At defined times coverslips were removed from Leighton tubes and the total treponemes per cell were counted using dark-field microscopy. Approximately 20 to 40 mammalian cells in duplicate or triplicate samples were counted. To obtain treponemes for virulence testing unattached treponemes were separated from cell-attached treponemes by removing the medium above the monolayer, which then contained the unattached treponemes. The tubes with treponemes attached to tissue culture cells were then washed twice with medium which was pooled with the previous medium. The tissue-culture cells were removed from the glass by the addition of fresh medium and gentle scraping with a rubber policeman. The suspension was pipetted several times in a $1-\mathrm{ml}$ pipette to break up the cell clumps and detach treponemes from the tissue-culture cells. Under dark-field microscopy treponemes were seen to be no longer attached to the tissue-culture cells. of These suspensions were centrifuged at $1000 \times g$ for $10 \stackrel{\Rightarrow}{\Rightarrow}$ minutes to sediment the mammalian cells. The $\stackrel{O}{\rightarrow}$ previously cell-associated treponemes, now in the supernatant, were counted and the concentrations of free and previously attached treponemes in the two suspensions were equalised before testing for virulence in rabbits. ${ }^{8}$ After intradermal inoculation the latent period for lesion development is inversely proportional to the number of virulent $T$ pallidum present in the injected sample. ${ }^{11}$ A shorter latent period indicated that a greater number of virulent $T$ pallidum were injected into the rabbit than in the case of a longer latent period. Student's $t$ test was used to compare differences. Differences between experimental groups were considered to be significant if $\mathrm{p}$ was less than $0 \cdot 05$.

\section{Results}

COMPARISON OF MAMMALIAN CELL LINES FOR ATTACHMENT OF T PALLIDUM

Freshly extracted treponemes attached to all five cell lines within 15 minutes, confirming previous observations $s^{56}$ that virulent treponemes readily attach to cultured mammalian cells. The number of treponemes per mammalian cell was maximal after 2-4 hours' aerobic co-incubation, and after 24-28 hours' microaerophilic co-incubation, for all cell lines tested. Hence, for further experiments the degree of adherence of treponemes was measured between 2-4 hours under aerobic conditions and at 24 hours under microaerophilic conditions.

The number of treponemes attached per mammalian cell is shown in fig 1 . More treponemes attached to rabbit and hamster fibroblast cell types (BRGO, RT, and BHK) than to human epithelial tumour cells (HT29, C76/203, and MCF-7). The number of treponemes attached per BRGO cell was significantly higher $(p<0.001)$ than in other cell lines under both aerobic and microaerophilic conditions. Furthermore, treponemes survived longer in the presence of BRGO cell than in other cell lines as measured by the retention of treponemal motility (fig 1). For subsequent experiments only BRGO cells were used.

\section{COMPARISON OF MEDIA FOR ATTACHMENT OF} TREPONEMES TO BRGO CELLS

Different culture media were used to compare attachment of $T$ pallidum to BRGO tissue-culture cells. Among four tissue-culture media tested a significantly greater $(p<0.001)$ number of treponemes attached per BRGO cell in EMEM than in other culture media under both aerobic and microaerophilic 


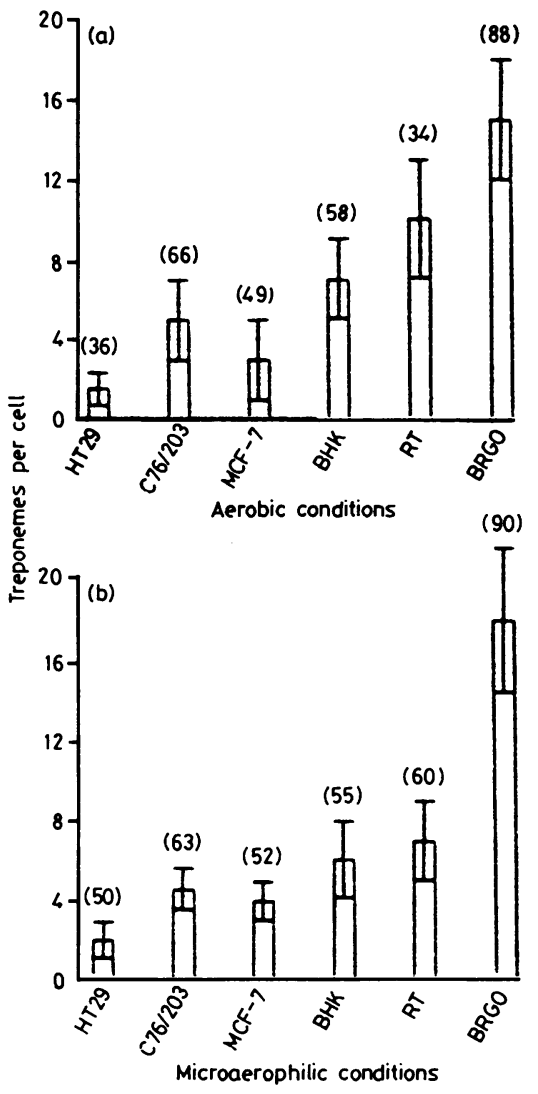

Fig 1 Comparison of different mammalian cell lines for the attachment of $T$ pallidum (HT29=colon tumour; C76/203 = skin tumour; $M C F-7=$ breast tumour; $B H K=$ baby hamster kidney; $R T=$ rabbit testes; $B R G O=$ baby rabbit genital organ.) Each bar represents the mean of 20 to 40 determinations \pm one standard deviation (SD). The numbers in parentheses indicate the mean of percentage motility of $T$ pallidum in duplicate or triplicate samples after three hours' (aerobic) or 48 hours' (microaerophilic) co-incubation with BRGO cells.

conditions (fig 2). The percentage motility of $T$ pallidum was also greater in EMEM than in other culture media (fig 2). For subsequent experiments EMEM was chosen as the medium for co-incubation of $T$ pallidum and tissue-culture cells.

\section{EFFECT OF DIFFERENT CONCENTRATIONS OF DTT} ON THE ATTACHMENT OF T PALLIDUM TO BRGO CELLS UNDER AEROBIC CONDITIONS

Reducing agents are generally used to reduce oxygen toxicity for $T$ pallidum in vitro. ${ }^{12}$ Sodium thioglycollate $^{13}$ has been shown to be toxic to treponemes, while DTT enhanced the viability of $T$

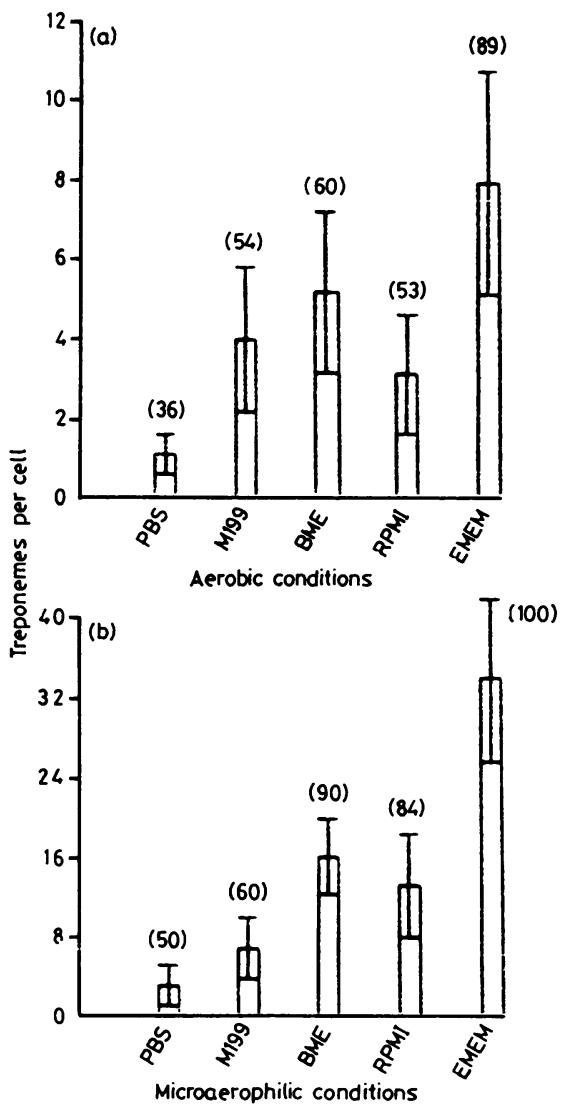

Fig 2 Comparison of different media for attachment of $T$ pallidum to BRGO cells under (a) aerobic and (b) microaerophilic conditions $(P B S=$ phosphate-buffered saline; $M 199=$ medium 199; $B M E=$ basal medium, Eagle; RPMI = Roswell Park Memorial Institute medium 1640; $E M E M=$ Eagle's minimal essential medium.) Each bar represents the mean of 20 to 40 determinations $\pm 1 S D$. The numbers in parentheses indicate the mean of percentage motility of treponemes in duplicate or triplicate samples after two hours' (aerobic) or 24 hours' (microaerophilic) co-incubation.

pallidum in vitro. ${ }^{12}$ The survival of $T$ pallidum in tissue-culture systems is, however, directly dependent on the metabolic state of the host. ${ }^{1}$ DTT is less toxic to tissue-culture cells than other commonly used reducing agents such as cysteine and reduced glutathione. ${ }^{14}$ When the effect of different concentrations of DTT $(0.25,0.5,0.75$, and 1 $\mathrm{mmol} / \mathrm{l})$ on treponemal attachment to cultured cells was examined $T$ pallidum were found to attach more rapidly to BRGO cells in the absence of DTT during the first hour of co-incubation. After three hours' coincubation, however, the attachment was the same in all cultures and the percentage motility of treponemes was not significantly different (data not shown). 
COMPARISON OF THE SURVIVAL OF FREE AND CELL-ATTACHED TREPONEMES

$T$ pallidum survives longer in the presence of tissueculture cells than in cell-free systems. ${ }^{12}$ The survival of free and attached treponemes co-incubated with BRGO cells was compared under microaerophilic conditions. The percentage motility of attached treponemes was higher than that of unattached treponemes (fig 3a). There was approximately a $60 \%$ difference in percentage motility between attached and free treponemes after 96 hours in vitro.

When the virulence of free and attached treponemes was compared the latent periods for syphilitic lesion development in rabbits were significantly shorter ( $<<0.001)$ for attached treponemes compared with unattached treponemes after both 72 and 96 hours in vitro (fig 3b). Attached treponemes survived significantly longer than unattached treponemes, indicating that direct attachment of the treponemes to the host cells enhanced the survival of T pallidum.

EFFECT OF AEROBIC, MICROAEROPHILIC, AND ANAEROBIC CONDITIONS ON THE ATTACHMENT OF TREPONEMES TO BRGO CELLS

$T$ pallidum has been considered to be either an anaerobe, ${ }^{15}$ an aerobe, ${ }^{16}$ or a microaerophile. ${ }^{17}$ The effect of these various environments on the attachment of treponemes to BRGO cells (fig 4b) and the retention of treponemal motility in the presence of BRGO cells (fig 4a) was studied. Under aerobic conditions the number of treponemes per cell was maximal after 2-4 hours' co-ir:cubation but dropped rapidly with time and finally maintained a plateau even when all treponemes (attached and unattached) were no longer motile.

Under anaerobic and microaerophilic conditions the extent of adherence increased with time to a maximum at between 24 and 96 hours. It was, however, significantly higher $(p<0.001)$ anaerobically than microaerophilically after 96 hours' incubation (fig 4b). The greatest percentage motility retention of treponemes occurred under anaerobic conditions followed by microaerophilic conditions. Aerobic retention of motility was poor and the fall in percentage motility paralleled the fall in the number of treponemes per cell. This result supports the hypothesis that $T$ pallidum is extremely sensitive to oxygen toxicity ${ }^{9}$ and that the extent of host celladherence is dependent on the viability of the treponemes.

\section{EFFECT OF DIFFERENT CONCENTRATIONS OF TREPONEMES ON THEIR ATTACHMENT TO BRGO CELLS}

It has been suggested ${ }^{6}$ that the attachment of treponemes to tissue-culture cells is due to specific receptor sites on the mammalian cells. If this is true, once all the receptor sites on the cells have been occupied no more treponemes would be able to attach to the host cells.

To test this hypothesis different concentrations of treponemes $\left(7.5 \times 10^{6}\right.$ to $\left.5 \times 10^{7} / \mathrm{ml}\right)$ were used as inocula for a fixed number of BRGO cells (approximately $10^{4} /$ tube). When the inoculum was $7.5 \times 10^{6}$ treponemes $/ \mathrm{ml}$ fewer than 10 treponemes attached per cell under aerobic or microaerophilic conditions. When $5 \times 10^{7}$ treponemes $/ \mathrm{ml}$ were used approximately 30 treponemes attached per cell under aerobic conditions and approximately 45 treponemes under microaerophilic conditions (fig 5), probably owing to the higher percentage motility of treponemes under microaerophilic than aerobic conditions. Hence, the degree of attachment of treponemes to tissue cells seems to be a linear function of the concentration of viable treponemes in the inoculum, within the range of concentrations studied.

\section{EFFECT OF AGE OF BRGO CELLS ON THE} ATTACHMENT OF TREPONEMES

BRGO cell monolayers at different levels of confluency (and hence different growth rates) were prepared by inoculating Leighton tubes with $10^{4}$ cells and incubating for between one and six days before inoculation with $T$ pallidum. The metabolism of the BRGO cells varied from rapid growth in 2-3 days after seeding to slow growth in 4-6 days after seeding. The cells were approximately $15 \%, 25 \%, 50 \%, 75 \%$, and $100 \%$ confluent at one, two, three, four, and six days respectively after seeding. Significantly greater $(\mathrm{p}<0.001)$ numbers of treponemes attached to cells at low densities than to cells near confluency under both aerobic and microaerophilic conditions (fig 6). These data suggest that $T$ pallidum preferentially attach to metabolically active host cells.

EFFECT OF DIFFERENT BRGO CELL DENSITIES ON THE ATTACHMENT OF TREPONEMES

To test further whether attachment was dependent on host metabolic state different growth rates of BRGO cells were obtained by seeding the Leighton tubes with different numbers of cells $\left(10^{3}\right.$ to $10^{5} /$ tube). After $1-2$ days' incubation at $37^{\circ} \mathrm{C}$ tubes seeded at the higher densities were nearly $100 \%$ confluent while tubes seeded at lower densities were still actively growing. The cell monolayers were approximately $20 \%, 40 \%$, $60 \%$, or $100 \%$ confluent after seeding with either $10^{3}$, $2 \times 10^{3}, 5 \times 10^{3}, 10^{4}$ or $10^{5}$ cells/tube respectively one day previously. Greater numbers of treponemes attached to actively growing BRGO cells $\left(1-3 \times 10^{3}\right)$ tube) than to the slower growing cells $\left(4 \times 10^{3}-10^{5} /\right.$ tube) under both aerobic and microaerophilic 

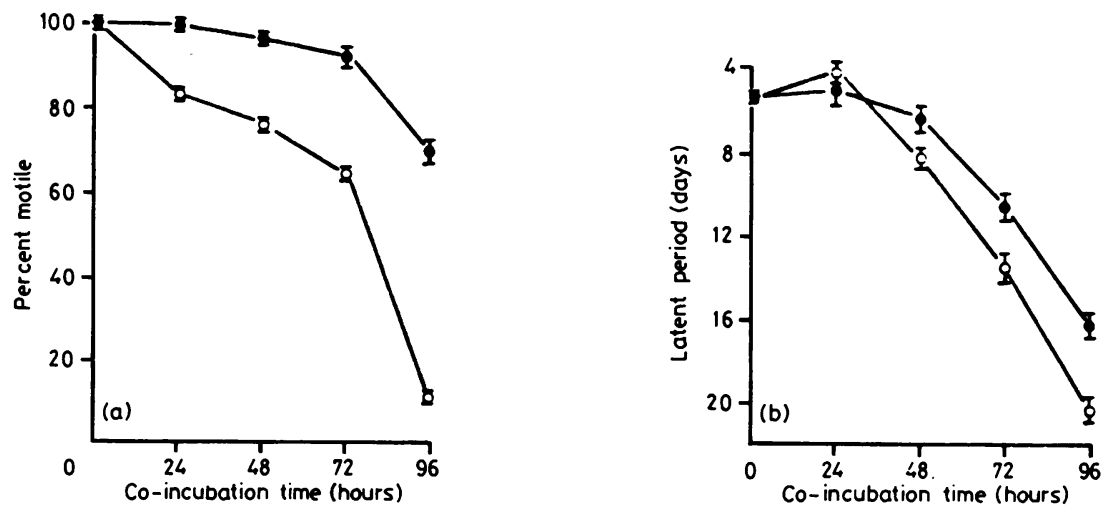

Fig 3 Comparison of the survival of unattached and attached treponemes to BRGO cells after different periods of microaerophilic incubation. (a) Percentage motility of $T$ pallidum; mean of duplicate or triplicate samples $\pm 1 S D$. (b) Latent periods (days) for syphilitic lesion development in rabbits; mean of six lesions in one rabbit \pm 1 SD. Both attached and unattached treponemes were tested on the same rabbit. $-T$ T pallidum attached to BRGO cells; $\bigcirc-O$ Unattached $T$ pallidum free in the supernatant of the tissue culture.
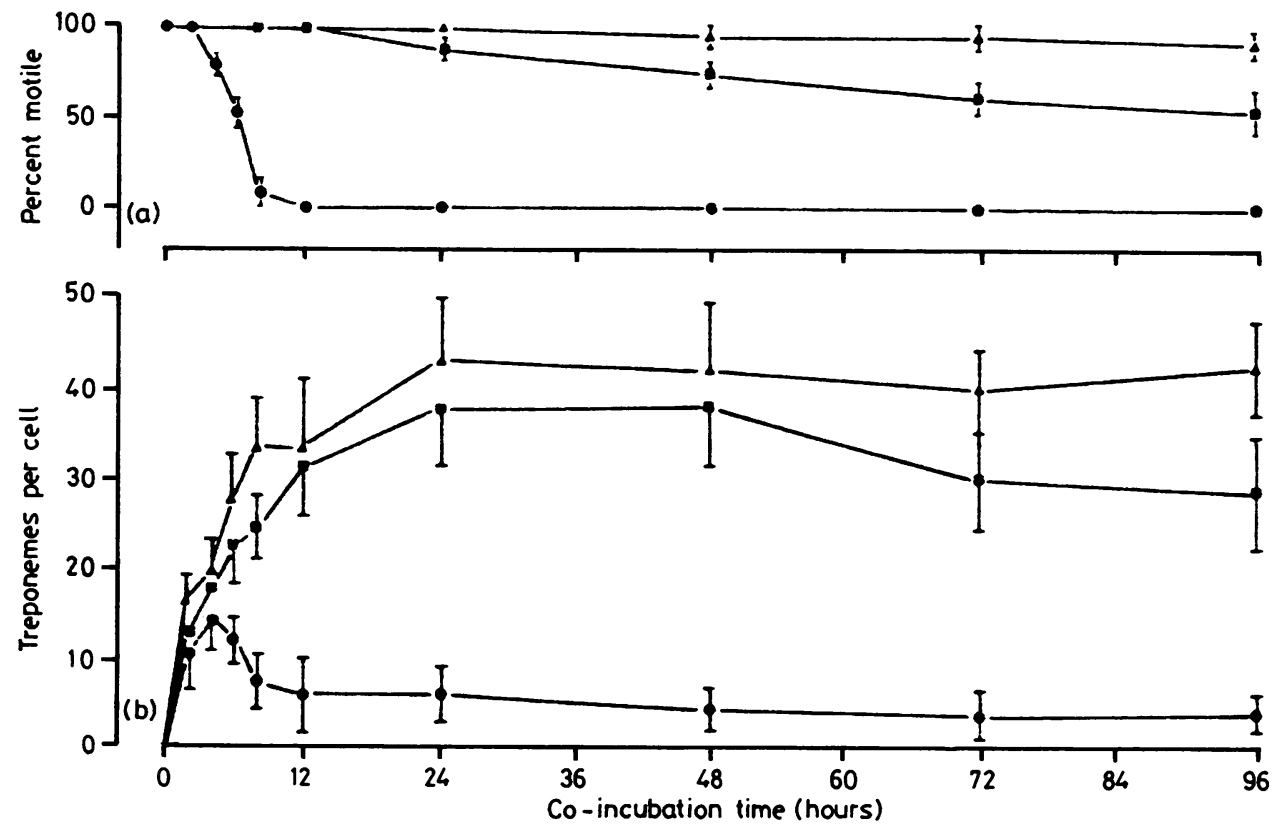

Fig 4 Effect of aerobic, microaerophilic, and anaerobic conditions on the attachment of treponemes to $B R G O$ cells. The extent of adherence of treponemes to BRGO cells was measured after different periods of incubation. Each point is the mean of 20 to 40 determinations $\pm 1 S D$. $\Delta-\triangle$ anaerobic co-incubation; 


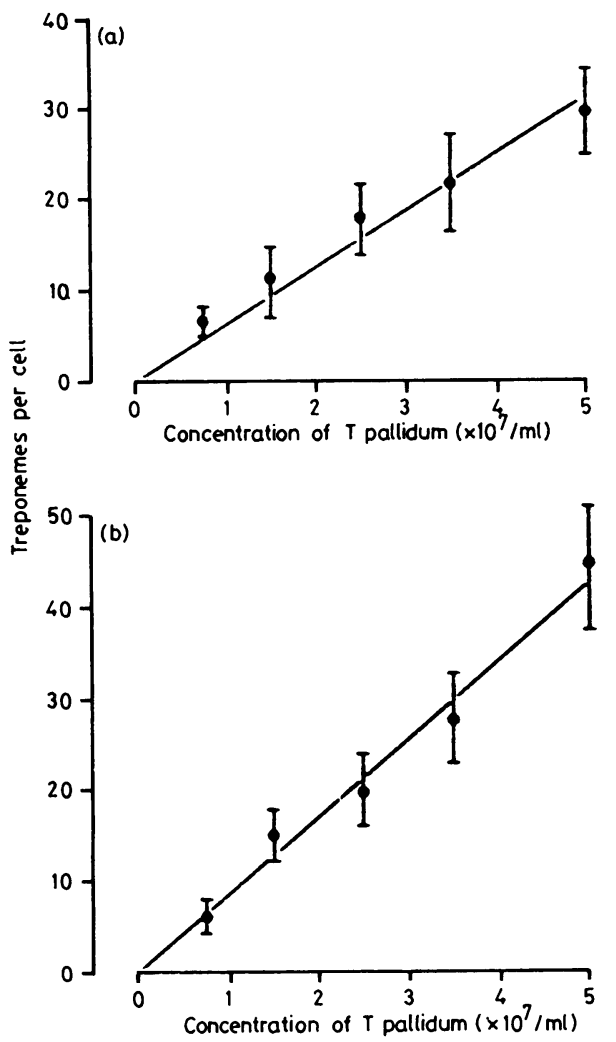

Fig 5 Effect of different concentrations of $T$ pallidum on their attachment to BRGO cells co-incubated (a) aerobically or (b) microaerophilically. Each point is the mean of 20 to 40 determinations \pm ISD.

conditions (fig 7). After 24 hours' microaerobic coincubation $T$ pallidum attached to approximately $100 \%$ of BRGO cells which had been seeded at $1-2 \times 10^{3} /$ tube one day previously. When $5 \times 10^{3}$ to $1 \times 10^{5}$ BRGO cells were used as the initial concentrations treponemes adhered to between $70 \%$ and $85 \%$ of BRGO cells. This difference was probably not due to an insufficient number of treponemes in the case of confluent BRGO cells since there was a 500 -fold multiplicity of treponemes to tissue cells in the cultures.

\section{Discussion}

A significantly greater number of treponemes attached to BRGO cells than to other cells (fig 1), indicating that these cells may be more susceptible to infection than the other cell lines tested. The reason for this is unknown. Also more treponemes attached to BRGO cells in EMEM supplemented with $10 \%$ FCS

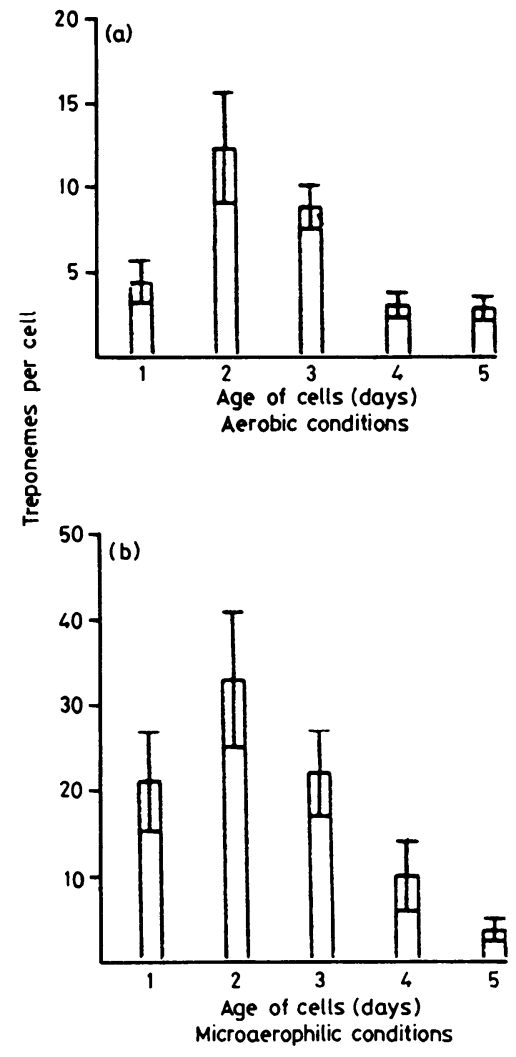

Fig 6 Effect of age of BRGO cells on the attachment of treponemes. Each bar represents, the mean of 20 to 40 determinations $\pm 1 S D$.

and $10 \mathrm{mmol} / \mathrm{l}$ HEPES compared with other media (fig 2). It is possible that BRGO cells, which were. originally isolated and maintained in EMEM, were not $\delta$ well adapted to other culture media. Alternatively, $T$ ₹ pallidum may survive better in EMEM than in other윽 tissue culture media. In the recent in-vitro cultivation $>$ of $T$ pallidum with rabbit epithelial cells in culture $e^{4}$ the medium was EMEM.

DTT $(0.25-1.0 \mathrm{mmol} / \mathrm{l})$ had no effect on the attachment of $T$ pallidum to BRGO cells although ${ }^{N}$ more treponemes attached to cells without DTT $N$ during the first hour of co-incubation. Previouslyo DTT was found to decrease DNA synthesis of BRGOo cells by $55 \%$ (Wong et al, unpublished data). Peterkofsky and Prather ${ }^{14}$ found that DTT inhibited $\stackrel{?}{+}$ the growth of chick embryo fibroblasts by $52 \%$ within 0 24 hours, and other reducing agents such as ascorbate, $\frac{\vec{P}}{0}$ glutathione, and cysteine were even more toxic to tissue-culture cells than DTT. Glutathione, cysteine, $\stackrel{\mathbb{D}}{\circ}$ and DTT also inhibited the response of nerve cells ing 


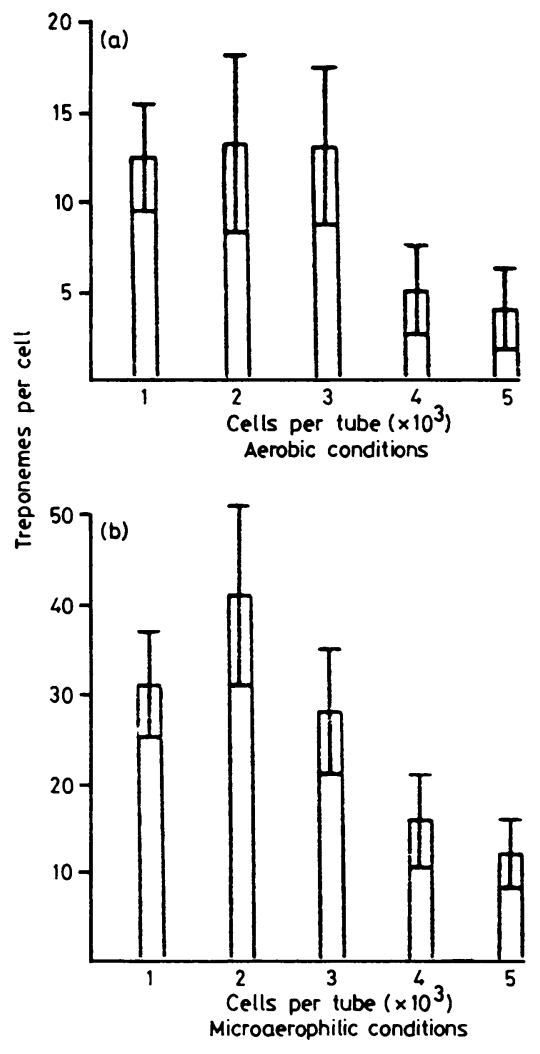

Fig 7 Effect of cell density of BRGO cells on the attachment of treponemes. Each bar represents the mean of 20 to 40 determinations $\pm 1 S D$.

culture to electrical stimulation (Fitzgerald, personal communication). The damage to tissue culture cells by reducing agents in the first inoculum may explain why they became refractory to treponemal attachment when exposed to a second fresh inoculum of $T$ pallidum. ${ }^{6}$ It may also explain why some workers have observed better survival of treponemes in cell-free systems than in tissue-culture systems. ${ }^{18} 19$ Excessive amounts of reducing agents may damage the tissue cells and thus indirectly kill the treponemes. The proper use of reducing agents is difficult since they must be in sufficient concentration to protect $T$ pallidum from oxygen toxicity yet not damage the tissue cells.

The survival of $T$ pallidum was prolonged in a variety of cell lines derived from human and animal tissue. ${ }^{2-7}$ Attached treponemes survived longer than unattached treponemes (fig 3), indicating the importance of cell attachment for the treponeme, although the role of cell attachment in infection is not clear. It may be necessary for $T$ pallidum to attach to a host cell surface before the treponemes can divide. If this is the case, one of the newly divided treponemes will still attach to the host cell by one end, while the other will be set free or be attached to another site on the host cell after division. This process may be the method by which $T$ pallidum multiplies in vivo ${ }^{1}$ and in vitro. ${ }^{4}$ Hence, tissue culture may well be essential for successful cultivation and subculture of $T$ pallidum in vitro. The superior survival of attached compared with unattached treponemes may also be due to direct uptake of essential nutrients or growth factors from the host cells or to reduction of oxygen toxicity by oxygen-protective enzymes present in the tissueculture cells (Steiner $e t$ al, unpublished data).

It is still not completely clear whether $T$ pallidum is an anaerobe, aerobe, or microaerophile. T pallidum is extremely sensitive to oxygen ${ }^{9}$ even in the presence of tissue cells and oxygen protective enzymes (Steiner $e t$ $a l$, unpublished data). The total number of treponemes attached per BRGO cell seemed to be a function of viable treponeme concentration (fig 5) under the three levels of oxygenation tested. After 12 hours' aerobic co-incubation all the treponemes were non-motile and the degree of cell adherence fell (fig 4). $T$ pallidum maintained a higher percentage motility under both microaerophilic and anaerobic conditions and the extent of cell adherence increased during the first 24 hours (fig 4).

The attachment of $T$ pallidum to tissue-culture cells may be a dynamic equilibrium as follows:

$\underset{\text { (unattached) }}{\mathrm{TP}}+\mathrm{TC} \underset{\mathrm{R}_{2}}{\stackrel{\mathrm{R}_{1}}{\rightleftharpoons}}$ (attached)

where $\mathrm{Tp}$ are viable $T$ pallidum and TC are tissueculture cells. $R_{1}$ and $R_{2}$ are attachment and detachment rates respectively. If treponemes are viable $R_{1}$ is probably faster than $R_{2}$ and the equilibrium will be to the right so that more treponemes continually attach to the TC cells. When the rate of attachment equals the rate of detachment $\left(R_{1}=R_{2}\right)$ a state of dynamic equilibrium would exist. When the treponemes detach they may become nonmotile and non-viable so that they lose the ability to readhere to the host cells. If this occurs excessively, $\mathbf{R}_{1}$ being less than $R_{2}$, the number of treponemes attached per cell will fall. This is, in fact, what we observed (fig 4) under aerobic conditions. If attached treponemes lose viability and become non-motile, they may remain adherent to tissue-culture cells. Such a plateau concentration of attached non-viable treponemes was observed under aerobic conditions (12-96 hours) (fig 4). The increase in the number of attached treponemes under microaerophilic or anaerobic conditions during 
the first 24 hours of incubation may, however, also suggest the possibility of replication by attached treponemes. The above events may also occur in vivo. Once $T$ pallidum enters the host some of the treponemes attach to tissue cells and multiply locally. Some treponemes will circulate and subsequently cause generalised systemic infection. ${ }^{1}$ Treponemes may selectively attach to certain tissues which contain high concentrations of glycosaminoglycan, ${ }^{1}$ such as dermis, testes, aorta, eye, placenta, and umbilical cord, or rapidly metabolising tissues, such as the germinal epithelium of the rabbit testes 20 and granulating wound tissue of rabbits and humans, ${ }^{21}$ or both. In vitro more treponemes attached to actively growing cells than to slowly growing cells (figs 6 and 7). These results suggest that the attachment of treponemes to tissue cells not only depends on the viability of treponemes but also on an active metabolic state of the host.

Specific receptor sites may be involved in the attachment of treponemes to the tissue culture cells. ${ }^{6}$ Within the range tested we found that the higher the concentration of viable treponemes inoculated the more treponemes attached per BRGO cell (fig 5). These results suggest that the attachment of treponemes to tissue-culture cells is unlikely to be dependent on a limited number of specific receptor sites on the host cells. If receptor sites are involved in the attachment of treponemes to tissue-culture cells then these receptor sites are probably non-specific, in large numbers, and uniformly distributed over the surface of the cells. The non-specificity of the attachment of treponemes is further supported by the fact that they attach to a variety of cells derived from different sources and even stick to glass (unpublished data). Hayes $e t \mathrm{al}^{6}$ found that the receptor sites for $T$ pallidum on mammalian cells were not degraded by trypsin, papain, or lysozyme, and these enzymes did not dislodge treponemes which had already adhered to the tissue cells. Fitzgerald et $a^{22}$ suggested that an intact layer of glycosaminoglycan which is present in many different types of tissue cells might be the site of attachment by $T$ pallidum by means of a treponemal glycosaminoglycanase. ${ }^{23}$ Several types of receptors have been detected on $T$ pallidum, ${ }^{24}{ }^{25}$ but the receptors in tissue-culture cells are still unknown. It is also possible that an outer protective layer present in $T$ pallidum ${ }^{26}$ may play an important role in treponemal attachment to host cells.

The study of the attachment of treponemes to the host cells is not only important for understanding the pathogenesis of syphilis but probably also for enhancing the multiplication of $T$ pallidum in vitro. It is possible that only host-cell-attached treponemes can divide, thus explaining the obligate parasitic nature of $T$ pallidum.
This work was supported by grants from the Australian National Health and Medical Research Council (NH \& MRC), the Utah Foundation, the $\vec{F}$ Heiser Program, The Australian-Britain Society, and $\stackrel{5}{+}$ Monash University, from whom funds are gratefully acknowledged. We thank Dr B Adler, Dr K N Wynne 흠 and Dr $P$ Sutrave for constructive criticism of the manuscript and Mrs L Drummond, for assistance in manuscript preparation.

\section{References}

1. Fitzgerald TJ. Pathogenesis and immunology of Treponema $\stackrel{\infty}{=}$ pallidum. Ann Rev Microbiol 1981;35:29-54.

2. Fitzgerald TJ. A review of recent studies on the in-vitro cultivation of Treponema pallidum. Bull WHO 1981.

3. Sandok PL, Jenkin HM, Matthews HM, Roberts MS. i Unsustained multiplication of Treponema pallidum (Nichols virulent strain) in vitro in the presence of oxygen. Infect Immun 윽 1978; 19:421-9.

4. Fieldsteel AH, Cox DL, Moekli RA. Cultivation of virulent $\overrightarrow{-}$ Treponema pallidum in tissue culture. Infect Immun 1981;32:908-15.

5. Fitzgerald TJ, Johnson RC, Miller JN, Sykes JA. 元 Characterization of the attachment of Treponema pallidum (Nichols strain) to cultured mammalian cells and the potential relationship of attachment to pathogenicity. Infect Immun 1977;18:467-78.

6. Hayes NS, Muse KE, Collier AM, Baseman JB. Parasitism by virulent Treponema pallidum of host cell surfaces. Infect Immun 1977;17:174-86.

7. Fieldsteel AH, Stout JG, Becker FA. Comparative behaviour of virulent strains of Treponema pallidum and Treponema pertenue in gradient cultures of various mammalian cells. Infect Immun 1979;24:337-45.

8. Steiner B, McLean I, Graves S. Redox potential and survival of

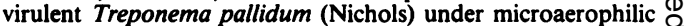
conditions. Br J Vener Dis 1981;57:295-301.

9. Wong GHW, Steiner BM, Graves SR. A comparison of $\overline{\bar{O}}$ anaerobic and microaerophilic conditions of extraction and 3 incubation on the survival of Treponema pallidum in vitro. $B r J$ Vener Dis 1982;58:139-42.

10. Wong GHW, Steiner BM, Graves SR. The lack of effect of bicarbonate on the survival of Treponema pallidum (Nichols) in vitro. Br J Vener Dis, in press.

11. Graves S, Sandok P, Jenkin H, Johnson RC. Retention of motility and virulence of Treponema pallidum (Nichols strain) in vitro. Infect Immun 1975; 12:1116-20.

12. Fitzgerald TJ, Johnson RC, Wolff ET. Sulphydryl oxidation $\bigcirc$ using procedures and experimental conditions commonly used $\frac{3}{3}$ for Treponema pallidum. Br J Vener Dis 1980;56:129-36.

13. Chalmers WSK, Taylor-Robinson $D$. The effect of reducing and $O$ other agents on the motility of Treponema pallidum in an acellular culture medium. J Gen Microbiol 1979;114:443-47.

14. Peterkofsky B, Prather W. Cytotoxicity of ascorbate and other reducing agents towards cultured fibroblasts as a result of hydrogen peroxide formation. J Cell Physiol 1977;90:61-70.

15. Harvath I, Duncan WP, Bullard JC. Cultivation of pathogenic Treponema pallidum in vitro. Acta Microbiol Acad Sci Hung N 1981;28:7-24.

16. Baseman JB, Nichols JC, Hayes NS. Virulent Treponema $\mathrm{\omega}$ pallidum: aerobe or anaerobe. Infect Immun 1976;13:704-11.

17. Graves S, Billington T. Optimum concentration of dissolved $<$ oxygen for the survival of virulent Treponema pallidum under $Q$ conditions of low oxidation-reduction potential. BrJ Vener Dis $\frac{\bar{D}}{\mathbb{D}}$ 1979;55:387-93.

18. Rathlev $T$. Investigations on in vitro survival and virulence of $T$. pallidum under aerobiosis. Br J Vener Dis 1975;51:296-300.

19. Kiraly K, Horvath I. Survival of $T$ pallidum under microaerobic $\bar{O}$ conditions in cell and tissue cultures. Zentralbl Bakteriol (Orig A) 1976;235:500-5.

20. Fraser $\mathrm{C}, \mathrm{Hu} \mathrm{C}, \mathrm{Ma} \mathbf{W}$. Relation of the changes in testicular $\mathbb{D}$ structure induced in the rabbit by estrogenic substances to $ᄋ$ resistance against syphilis. Endocrinology 1941;29:218-24. 
21. Chesney A, Turner T, Haney C. Studies in experimental syphilis VIII. On the localization of syphilitic lesions in inflamed areas. Bull Johns Hopkins Hosp 1928;42:319-34.

22. Fitzgerald TJ, Johnson RC, Ritzi DM. Relationship of Treponema pallidum to acidic mucopolysaccharides. Infect Immun 1979;24:252-60.

23. Fitzgerald TJ, Johnson RC. Mucopolysaccharidase of Treponema pallidum. Infect Immun 1979;24:261-8.

24. Baseman JB, Hayes EC. Molecular characterization of receptor binding proteins and immunogens of virulent Treponeme pallidum. J Exp Med 1980;151:573-86.
25. Alderete JF, Baseman JB. Analysis of serum IgG against Treponema pallidum protein antigens in experimentally infected rabbits. Br J Vener Dis 1981;57:302-8.

26. Zeigler JA, Jones AM, Jones RH, Kubica KM. Demonstration of extracellular material at the surfaces of pathogenic $T$ pallidum cells. Br J Vener Dis 1976;52:1-8. 